\title{
Making it too simple? Researchers, recommendations, and NGOs in the Sundarbans, Indian West Bengal
}

\author{
Cathy Rozel Farnworth, ${ }^{\text {a, } *}$ Independent Consultant \\ Mette Vaarst, ${ }^{\mathrm{b}}$ Aarhus University
}

Submitted 9 December 2010 / Revised 22 June 2011, 13 November 2011, 24 November 2011, 11 March 2012, and 3 June 2012 / Accepted 3 June 2012 / Published online 16 July 2012 / Updated online 11 September 2012

Citation: Farnworth, C. R., \& Vaarst, M. (2012). Making it too simple? Researchers, recommendations, and NGOs in the Sundarbans, Indian West Bengal. Journal of Agriculture, Food Systems, and Community Development, 2(4), 137-146.

http://dx.doi.org/10.5304/jafscd.2012.024.001

Copyright (C) 2012 by New Leaf Associates, Inc.

\begin{abstract}
The authors are members of an international study team that conducted research on one of the islands making up the Sundarbans region of West Bengal in India in September 2008. This was at the request of two nongovernmental organizations (NGOs), one European and one Indian, which have partnered with each other to bring long-term development to this desperately poor area. The purpose of the research was to analyze existing agricultural
\end{abstract}

a, * Corresponding author: Freelance consultant on gender, agriculture, and value chains based in Germany; cathyfarnworth@hotmail.com

b Faculty of Agricultural Sciences, Aarhus University, P.O. Box 50, DK - 8830 Tjele, Denmark; +45 22901344; Mette.Vaarst@agrsci.dk

Correction: This paper was updated on 11 September 2012 to remove two photographs included in the original, per the authors' request. practices and to develop recommendations for the two partner NGOs on how to work with farmers toward more sustainable, low-input farming systems that would contribute to poverty alleviation and simultaneously address some of the serious challenges of climate change affecting the lives of millions living in this low-lying region.

This paper brings together personal reflections by two members of the study team upon the research process and, more particularly, on the take-up of recommendations. The starting point for this paper is the observation that the recommendations were implemented by the two NGOs with more concern for meeting the needs of the NGOs, rather than the needs of the farmers the research was ultimately intended to serve. Followup visits after six and 18 months showed that an organic demonstration farm had been developed in preference to rolling out recommendations aimed at supporting change in farming practice on 
individual farms and on involving people with the most precarious livelihoods. The paper explores the bumpy nature of the relationship between the researchers, the two NGOs, and the intended ultimate beneficiaries.

\section{Keywords}

Indian West Bengal, interdisciplinary research, livelihoods, sustainable agriculture

\section{Introduction}

The Sundarbans region in Indian West Bengal is low-lying and composed of many islands watered by inlets from rivers and the Bay of Bengal (see figure 1). The capacity of the agrarian population to establish resilient farming systems is of paramount importance if the current high rates of landloss due to coastal erosion and other changes brought about by climate change are to be mitigated. Should resettlement prove the only option, the population requires the capacity to develop innovative, low-cost farming systems wherever they are settled.

Farmers living in the Sundarbans are anxious to find ways to tackle the many challenges facing them. In 2007, farmers on Basanti Island participated in a Farmer Field School "training of trainers" course. They expressed deep concern about the limits to food production, and environmental changes, in the area. In their view, crop yields over the past few decades had declined sharply, while fish species were disappearing and weather conditions were increasingly erratic. They were keen to identify strategies for sustainable agricultural practices. As a consequence of these discussions, and at the invitation of the Indian NGO that hosted the Farmer Field School groups, the second author of this paper formed an international, multidisciplinary study team to explore the farmers' requests for assistance in more depth. The study team worked on Basanti Island for three weeks in September 2008 with the assistance of a European NGO that raises and allocates funds for work with partners in the Global South, including the Indian NGO that has representation in Europe. Following the conclusion of the fieldwork and the production of two reports containing findings and recommendations, two more visits were made at the invitation of the host NGOs, six months and 18 months later, in order to track the implementation of the study team's recommendations.

In this paper we discuss how our recommendations, agreed to by all partners, were selectively

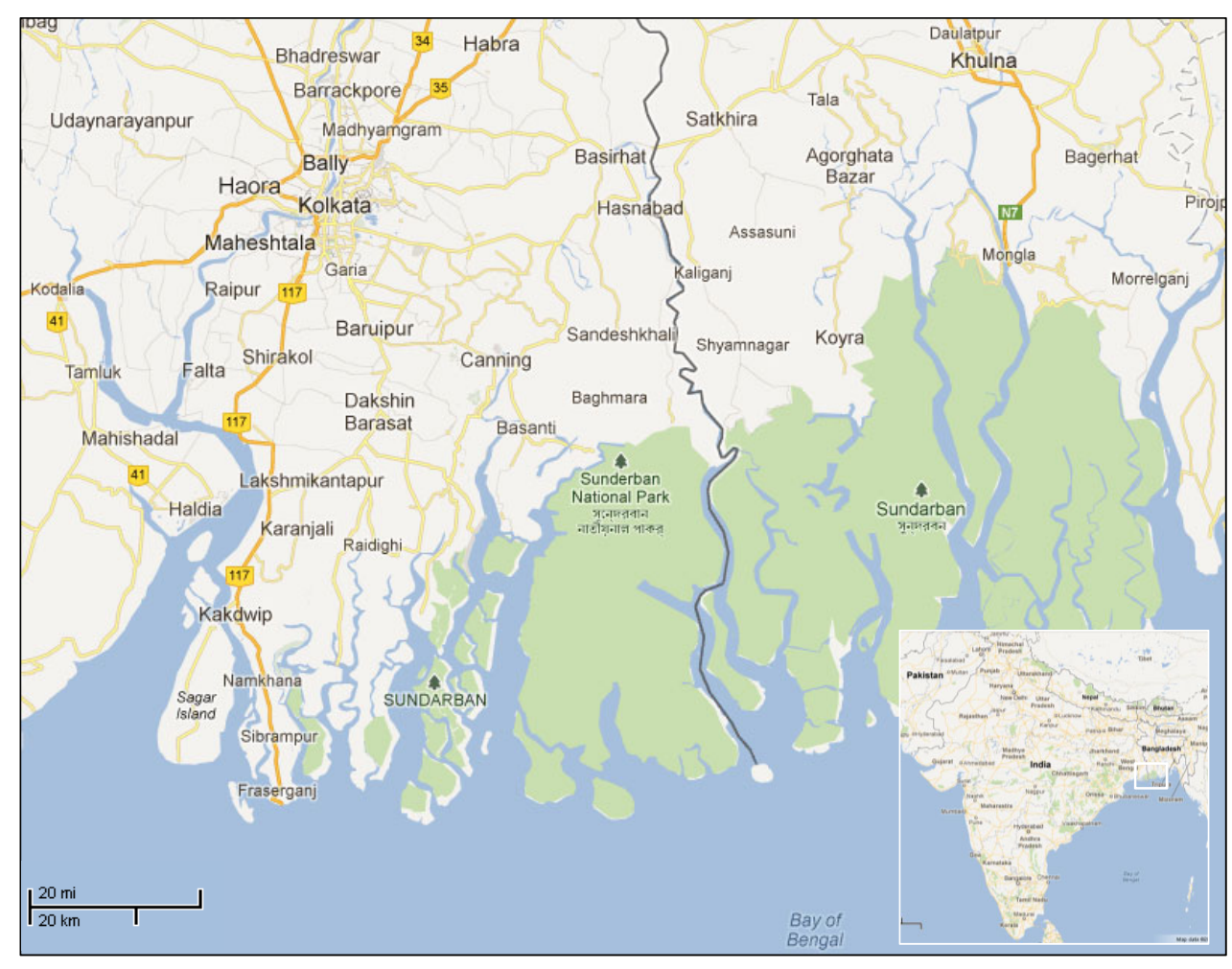

Figure 1. The Sundarbans region of Indian West Bengal.

Map data (c) 2012 Google, AutoNavi, MaplT, MapKing, Tele Atlas 
implemented, and as a consequence failed to meet the expressed needs of the farmers. The two NGOs did not capitalize upon the research findings in order to offer a comprehensive strategy for working with farmers on strengthening and diversifying their livelihoods. As researchers, we feel that our experience is an important one, that it is far from atypical, and that for this reason it is important to share. Our experience touches upon the expectations all parties to a research process may have. The development partners (in this case, two NGOs) expect recommendations they can and would like to - implement to be the chief outcome of the research process. The target beneficiaries (in this case, farmers) participate in the hope that real change may come about through the sharing of their challenges and aspirations with the research team. We think that it is impossible for us, as researchers, to be neutral in such a situation. This is because we adopt the social constructionist position that knowledge is created rather than found through complex researcher-respondent interactions. This means that the "findings" are not value-free but rather a shared product that can, and indeed should, form the basis of negotiations between key actors. While researcher involvement tends to end with delivery of a final report, in this case we were able to observe, due to long-term interactions with the two NGOs during implementation, that interlinked recommendations designed to be mutually supportive and to "make a difference" were rejected in favor of simple, easily packaged recommendations that floated almost free of context, did not solicit meaningful beneficiary engagement, and did not support the wider development of sustainable farming practices in the area. In view of the challenges the research was originally commissioned to address, this was a disappointing outcome.

The paper continues by providing an overview of the problem situation. This is followed by a summary of the research design. The research findings were very comprehensive and are not discussed in this paper, although one key finding that had a bearing on the chief research purpose is presented. The nub of the paper lies in the recommendations. These are summarized and followed by a discussion.

\section{The Sundarbans Research Area}

The project team undertook its research on Basanti Island in the Sundarbans in Indian West Bengal. The Sundarbans is the largest delta region in the world, with the waters of the Ganges, Brahmaputra, and Meghta draining into the Bay of Bengal. Comprising vast mangrove forests with an area of 3,860 square miles $(10,000$ square $\mathrm{km})$, the Sundarbans spills across Bangladesh and India. In 2001 the Sundarbans Reserved Forest in India was declared a Global Biosphere Reserve. The climate is tropical, with a monsoon season from early June to mid-September with annual rainfalls of about 63-71 inches $(1,600-1,800 \mathrm{~mm})$. The area is prone to cyclones, with an average of 4.4 cyclones annually. Soils range from sandy to clay loams (IFAD, 2008a).

A United Nations Development Programme (1999) assessment notes that the Sundarbans was managed fairly well under seminatural conditions for decades. However, traditional user practices have largely broken down due to poverty and population pressure, a lack of trust between government departments and the local communities, and a perceived lack of viable livelihood alternatives. The majority of livelihood activities are now unsustainable, resulting in depletion of the Sundarbans ecosystem and high levels of social inequality. The World Bank (2009) notes that coastal areas across the whole of South Asia, including the Sundarbans, are highly vulnerable to flooding as a consequence of climate change. Interacting pressures include high population densities, a large concentration of poverty, and climate variability.

It is estimated that approximately eight million people in India and Bangladesh depend directly upon the Sundarbans for their livelihoods. Of these people, around 44 percent belong to Scheduled Castes and Scheduled Tribes. ${ }^{1}$ Almost

\footnotetext{
${ }^{1}$ The Scheduled Castes (SCs), also known as the Dalit, and the Scheduled Tribes (STs) are two groupings of historically disadvantaged people who are given express recognition in the Constitution of India. The Scheduled Castes and Scheduled Tribes make up around 15 percent and 7.5 percent, respectively, of the population of India, or around 24 percent altogether, according to the 2001 Census. The Constitution (Scheduled Castes) Order, 1950 lists 1,108 castes across 25 states,
} 
the entire population, 85 percent, of the Indian Sundarbans relies on agriculture. Rice is a staple food and is grown between April and October. Landless agricultural laborers or marginal farmers compose around 90 percent of the cultivators in the area. The average farm size is less than 2.5 acres (one hectare). Of the approximately 50 percent of the population that is landless, around 15 percent do not have access to even a small parcel of land to build homes upon (UNDP, 1999).

Increasing production by expanding the area cultivated is not an option. Productivity is declining despite the heavy use of fertilizers. In areas with access to brackish water resources, rice-fish production takes place, whereby fish culture is undertaken following harvesting of the rice crop. This is achieved by permitting brackish water to enter the paddy field. The practice results in higher salinity levels in the paddy fields, creating a need for salt-tolerant varieties of rice. Women are heavily involved in fishing, particularly in farming prawns for export to the cities and overseas. Despite this high level of dependence on fishing, there has been very little investment in valueadding and marketing, keeping the incomes of the fishers low (UNDP, 1999). The production figures for fish and shrimp show a declining trend between 2003-04 and 2006-07 (Government of West Bengal, 2007). Important livestock include poultry, cattle, and goats. Sheep are less common, and pig production is very limited. A wide variety of vegetables and fruit are grown. Other agriculturally related occupations include honey collection, wood cutting, and handicraft production.

Infrastructure issues are challenges for successful farming. Marketing is dogged by poor road networks, with produce often being transported to market by individual farmers on small manually drawn rickshaws. At the time of the study on Basanti Island, there was no electricity (the nearest lines are about 6.2 miles or $10 \mathrm{~km}$ away), although plans are underway to electrify the island. Lack of electricity hinders the development of temperaturecontrolled supply chains and the storage of vac-

while the Constitution (Scheduled Tribes) Order, 1950 lists

744 tribes across 22 states (Scheduled castes and scheduled tribes, 2012). cines, as well as industrial development. Borrowing is an important means of meeting basic needs. According to an IFAD (2008a) study, levels of borrowing vary between 41 percent and 25.6 percent. Money lenders tend to charge a very high rate of interest.

In West Bengal as a whole, 27 percent of rural households hold a BPL (Below Poverty Line) card. This is similar to the national average of 26.5 percent (Government of India, 2004-2005). In West Bengal higher rates of poverty are experienced by the Scheduled Castes (37.5 percent BPL in 2005) and the Scheduled Tribes (28.7 percent BPL in 2005) (National Sample Survey Organisation [NSSO], 2005). Poverty is strongly correlated with size of land holding. In the state, 81 percent of BPL card holders have a farm area of 2.5 acres $(1 \mathrm{ha})$ or less. The landless represent 23 percent of BPL card holders. An IFAD study (2008b) used the number of meals taken in the household as a further indicator of poverty. This showed that in the three coastal districts of the Sundarbans studied, between 54 and 42 percent of households eats one square meal per day or less. Chronic energy deficiency, measured by the proportion of the population with a Body Mass Index below 18.5, is widespread. Among tribal populations in West Bengal, this reaches 42 percent among women and 32 percent among men (Das \&Bose, 2010).

\section{The Aim of the Research}

The overall objective of the study was to formulate a solid strategy to promote sustainable agroecological agricultural systems in the area. The fundamental tenet was that existing farming practices, and farmer knowledge, provide a platform upon which more systemic, less chemical inputintensive forms of farming can be developed. It was expected that the creation of integrated, diverse agricultural production systems based upon the local circulation of resources - manure, compost, fodder, and food - would contribute to the wider goals of the two NGOs: improved food security and nutrition, and increased incomes due to higher sales and lower expenditures on chemical inputs. The overall outcome was expected to be the generation of improved livelihoods for the farmers and their families over the long term. 
The underlying premise of the study is that farming should be conceptualized, and actively worked with, as a multipurpose activity capable of generating a variety of important benefits such as those just listed, and in so doing, help farmers achieve their self-defined vision of the "good life." With respect to global challenges, farming must sustain ecological functioning, promote biodiversity, and implement practices to mitigate climate change, for example, through sequestering carbon and preventing soil erosion.

\section{The Study Team}

In appreciation of the fact that the issues facing the farmers in the Sundarbans are highly complex, a multidisciplinary, multinational team was pulled together. Since Cuba lies in an agro-ecological zone similar to that prevailing in the research area and currently practices low-input farming, a Cuban agricultural scientist was invited to contribute his insights on how to innovate under difficult conditions using a variety of techniques. Two Indian agronomists seconded from an NGO working elsewhere in the Sundarbans were asked to examine crop and fishery production in the area, and to make suggestions based on their own experiences of using sustainable low-cost techniques in working with extremely poor people. A Danish soil scientist examined current practice in the area with regard to chemical inputs and assessed the impact of their use upon soil structure and quality, and a veterinarian studied animal husbandry practices. Two socio-economists from Britain and Bangladesh paid particular attention to food distribution practices within households, the gender division of labor in farming, and value chain development.

The research team worked closely with 10 midlevel Indian staff, women and men, who were employed long-term by the host Indian NGO. They had an in-depth knowledge of the agroecological conditions in the area, experience with the crop-livestock systems practiced, and had good relations with local people. To improve their research skills, the socio-economists trained the other team members in gender-sensitive participatory research methods each morning. The afternoons were devoted to parallel data-collection activities by the entire research team in three villages. Each evening, the entire team together with the NGO staff collectively analyzed the findings and considered the efficacy of the methods from the day's work. The NGO's senior management was present at all sessions and offered guidance and insights. Following this, the next day's fieldwork was planned.

\section{The Research Process}

The overall research program was discussed and agreed to between the study team members and the Indian NGO. It was based on a collectively agreedupon set of principles aiming to promote farmerformal-trained scientist learning (see table 1).

The thematic areas chosen for inquiry were food security and nutrition, crop and animal

\section{Table 1. Principles Agreed Upon for the Farmer-Formal-Trained Scientist Learning Research Program}

1. The farmer is the expert on his or her own farm.

2. The knowledge of the farmer is the basis for sustainable farmer-led future development. Farmer experience should consequently be the main source of information for any analysis of this area.

3. Farmers have agency. That is, they have the ability to define their goals and to act upon them. Agency can take the form of decision-making, bargaining and negotiation, deception and manipulation, subversion and resistance, as well as the processes of reflection and analysis.

4. For this reason, and as a matter of basic respect, farmer involvement in development plans is of crucial importance.

5. If we accept that reality is co-created in a research process (as opposed to merely being found), actions on the part of respondents, enumerators, and the researcher themselves will play a major role in determining the type of "reality" that is produced.

6. All stakeholders will be included. Discussions between team members prior to the field work resulted in an agreement that the research would be informed by all sectors of the community in the research area. We identified and met with landless families (who own the land on which their homestead stands, but no other land) and "homesteadless" people (who had been permitted to build a shelter on other people's land), including a group of organized landless women. All these people are involved in agriculture as laborers at various times of the year. 
husbandry practices, and locally important value chains. Food security in terms of availability and access to food was investigated through participatory analyses and key-informant interviews. Farming practices, farm structures, and the conditions for farming were studied through workshop sessions, soil testing, participatory seasonal calendars, and farm mapping. This was complemented by key-informant interviews with farmers, fishers, and local marketers of pesticides. All research aimed to be gender-sensitive and worked with sex-disaggregated data.

Accurate statistical data about the area and the population (such as demographics, income levels, etc.) was impossible to obtain due to a lack of systematic recording by local government departments. Validation of the findings was achieved through comprehensive cross-referencing of the thematic findings between all team members and NGO staff at the time of research and through reports co-written by all members of the international study team and shared with both NGOs. Key findings were translated into Bengali to help promote their dissemination to farmers in the area.

\section{Selected Research Findings}

Given the size of the study team (five international and two Indian NGO members) and ten seconded NGO staff, it was possible to collate, analyze, and interpret a huge amount of data. Since this paper focuses on the processes that prevented some of the evidence-based recommendations being taken up, we do not present the findings here except for one set central to the research project: farmer understanding of ecosystem principles. The research demonstrated that farmers were highly conscious of the costs of chemical inputs and the indebtedness that often resulted. They thought that "organic farming" meant excluding these chemicals. The fact that organic farming is a complex, knowledge-intensive, and context-dependent agricultural approach involving the whole farming system was not well understood. A disconnect between different areas on the farm was often demonstrated. For instance, many households did not use household waste other than that which could be used for animal fodder, nor did they use animal manure as a fertilizer, and there was no use of trees for animal feed despite the wide range of potentially useful trees in the area. At the same time, the farmers managed mixed crop-livestock farming systems. The study team felt that this provides an excellent basis upon which to build a more sustainable and systemically interlinked farming system.

\section{Recommendations}

The recommendations made by the study team were based upon an intensive process of verification with the NGO senior management teams, the farmers themselves, and the NGO staff involved in the fieldwork. The recommendations were further discussed and agreed upon in team meetings between the authors of the reports, the European NGO, and the Indian NGO. Within the framework of these recommendations, activity plans were developed. The key recommendations are presented in table 2 , along with a summary of the degree to which they were implemented by the Indian NGO after 18 months. This is followed by a discussion of the reasons why, in the study team's view, important recommendations were not taken up.

The critical point about sustainable, low-input farming is that it is based on complex intercropping systems. Switching to agro-ecological techniques demands high levels of farmer capacity, a willingness to innovate, and the ability to take some risk, particularly with respect to potential initial decreases in yield, insect attacks, and disease infestations. Since the majority of the farmers in the research area are very poor, even at the "high end," the demonstration farm (Recommendation 1) was recommended to help farmers observe the new techniques in practice before trying them out themselves. However, disappointingly, the demonstration farm became the focus of NGO efforts to the exclusion of almost all other recommendations, which were weakly implemented, if at all.

In particular, the outreach recommendations were lost. To foster farmer learning, a critical recommendation (No. 2) was that farmer learning groups should be established and directly involved in the planning and work on the demonstration farm. However, in reality all decisions regarding the planting and maintenance of the farm were taken 
Table 2. Recommendations Made by the Study Team and Degree of Implementation of Each

\section{Recommendation}

1. Organic demonstration farm set up.

2. On-farm demonstration of locally feasible agronomic techniques to both women and men in household on land set aside for this purpose, including for the most poor. Couple training required. Create farmer learning groups and involvement in managing the demonstration farm.

3. Long-term management structure set up to enable the host NGO to handle training and to ensure the demonstration farm is able to generate its own income. Aim is to eliminate dependency on NGO funding for farmworker salaries, etc. among target groups: farmers, program participants, and collaboration partners.

5. Further work on identifying and alleviating any programmatic weaknesses in the project. For example, a SWOT analysis was recommended as a basis for improving decision-making.

6. Differentiated targeting of beneficiaries.

\section{Degree of Implementation by NGO}

Main focus of NGO effort, and successfully completed.

All demonstrations were conducted only on the demonstration farm. Although the farm was visited by some farmers, there was no strategy for involving farmers and no guidance on how to use the demonstrations at home in the households and farms. Couples were rarely trained together.

This recommendation was partly targeted by another project focusing on capacity-building within the NGO.
4. Raising awareness about the aims of the project

This was implemented to a limited degree by informing village committee leaders, creating a song about the negative effects of pesticides, and inviting people to the demonstration farm.

A SWOT analysis was not performed, nor any other associated work.

This was implemented to a limited extent by involving farmers with different sized farms at differentiated training session at the demonstration farm. Farmers had to own land to be involved. Vulnerable women (widows, abandoned wives, and divorcees) and landless people were not explicitly targeted despite the strong recommendations made.

7. Marketing strategies developed.

The demonstration farm attempted to be a self-sustaining unit, so that farm workers were paid from income from the farm (selling its produce to the NGO kitchen and villagers). But since farmers were not organized, no joint marketing initiatives were set up with them.

The yields in terms of marketable crops from the demonstration farm were recorded and key staff members trained in this through the capacity development project described above. However, organic practices were not documented, resulting in an important loss of learning.

Demonstration farm workers were partially trained by the other NGO and by each other. No resource persons in the villages were trained.

There was neither time nor capacity to work on this.

10. Database on outcomes and experiences in use (see recommendation 8) set up.

11. School involvement. The involvement of three local schools was planned to enable children to come to the demonstration school and establish school kitchen gardens

12. Socially responsible food culture promoted.
This did not happen due to time to work on this not being set aside for key NGO staff members, and a lack of resources for implementation.

This was targeted by another project in the NGO focusing on birth control in the villages. Health workers encouraged families to adopt more equitable food habits. 
by the management. The Indian NGO justified this by arguing, for example, that the demonstration farm was too far from people's homes, and that the farmers did not have time to come, preferring to work on their own farms.

The consequence of the decision to centralize all decision-making and all work on the demonstration farm, as opposed to handing plots over for guided farmer management, was that the control over all variables - what is grown, who participates, the physical appearance of the farm, etc. stayed with the demonstration farm employees as well as the NGOs. This meant that the main aim of the demonstration farm, as envisioned in Recommendation 1, could not be realized: enabling the farmers to translate what they practiced on the demonstration farm into improved practices on their own land.

Recommendation 4 (and 6 to some degree), to target the most poor through the dissemination of proven techniques, was not realized. There appears to have been a deep reluctance to engage with landless people and the most poor beyond as beneficiaries, rather than as co-creators, of a program. This was evident during the research process itself; in one case landless women said they could scarcely scrape a living from making incense sticks and were then shouted at by NGO staff for lack of "gratitude." This generally paternalistic approach may have contributed to a second failure, namely the inability of the two Indian NGOs (the host NGO and the second Indian NGO involved in the research process) to collaborate beyond the research phase. Lack of collaboration meant that exciting opportunities to try out and disseminate techniques that had been successfully applied by the second Indian NGO was missed. These techniques had made a demonstrable difference in the lives of poor people. For example, one technique involved engaging landless people in organic farming through vermiculture production. This enabled them to make compost for sale and to create small mushroom and vegetable gardens in troughs set against the outside walls of their homes. Some of the worms were used to feed homestead chickens, thus providing a further income-generating opportunity. This NGO had also catalyzed processes in which landless women participated in sapling production, in creating tree plantations along roadsides and developing vegetable gardens on land leased from the government or from large farms.

Recommendation 9 (training of resource persons) was realized only in part, even though both the Indian and European NGO had argued this was a critical support component to the wider program. Over time, it became clear that the senior management of both NGOs were concerned that up-skilling staff would result in their leaving the Indian NGO for employment elsewhere, and they also were clearly concerned about upgrading the skills of villagers. The two NGOs were reluctant to consider developing incentives such as measures for staff mobility, improved salary structures, and other measures that could have counteracted a desire to leave. This said, local NGO staff capacity did improve despite the lack of organizational support. For instance, they became very knowledgeable with regard to the use of agro-ecological techniques (the use and making of compost, use of bio-pesticides, and a variety of intercropping techniques), and they also initiated a seed bank. This expansion in capacity was achieved primarily by the staff themselves, by sharing their experiences and with the encouragement of the demonstration farm manager, who placed a high value on communication and reflection.

\section{Concluding Remarks}

We feel that the choice of recommendations selected for implementation was based not upon a sober analysis of the most appropriate actions required to alleviate poverty and improve farming practice in the area, but rather upon a desire to implement activities that looked good and could be used to help "market" the work of the NGOs to a wider European and Indian audience. The messy and political work of considering who to target, the creation and implementation of appropriate outreach strategies, and fundamentally challenging the status quo in terms of NGO-beneficiary relations was not carried out. The failure to maximize and capitalize upon NGO staff and villager capacity is disappointing because the chance to build a cadre of local expertise has been lost. 
Investing in showcase projects that appeal to donors is simpler than the less showy, but far more important, work of engaging in on-farm trials and the participatory capacity-development programs necessary to enable farmers to understand and implement sustainable agro-ecological farming on their farms.

Working with the most poor, including women in general, people with very small plots of land, and landless women and men demands the capacity and willingness to openly engage in counteracting the structural biases that keep people poor in the area. Until now, the Indian NGO's work with the most poor has focused on small income-generation activities with low profit margins, and this is clearly its comfort zone.

The fact that farmers were not involved by the management board of the NGO in planning around the demonstration farm and other activities is a significant loss. It means that an explicitly participatory research process became, in the end, an extractive one: findings were selectively used by decision-makers without the participation of the intended beneficiary community who had contributed to the analyses.

In sum, it is clear that the results and recommendations of the research process have not been taken up in a way that significantly contributes towards the systemic change in farming practices so urgently needed in the Sundarbans.

\section{Recommendations}

Our experience shows that mutual expectations as to what the study could contribute, and the research principles upon which it was based, were not agreed upon sufficiently before the study was initiated. It is therefore vital to clarify expectations before study commences. Each partner should have a clear and agreed-upon role in the research process. The main beneficiary of the process should be clarified. This is easier to do when the beneficiaries - farmers in this case - are worked with as actors rather than as beneficiaries.

We recommend working with multidisciplinary and multinational teams, including country nationals. This will enable international members to test their assumptions and gain deeper understanding through international-national expert interactions. At the same time, international staff can contribute insights gained from their work in other countries. This may help in a "re-viewing" of the problem situation and broaden the range of potential solutions to be considered. The participation of national experts is absolutely critical because they will have the deep insights into the target society that are crucial to the research endeavor, they will speak the local language and be able to facilitate the research process in culturally appropriate ways, and their participation in formulating recommendations - together with the target group - will help to ensure that these are relevant and do-able.

A study that aims to be truly participatory and not all do - should include continuous feedback and reflection processes involving the host organizations, the research team, and the end users of the result (farmers and farmer representatives, including women and other often poorly represented members of society, such as landless people and male and female youth) while the research team is still in situ. It is our view that farmer involvement, influence, and participation throughout the whole process, including all steps in the implementation process, should be placed at the center of any agricultural development project, and a clear outreach strategy should be agreed upon. This should provide scope for iteration and modification through a good monitoring and evaluation $(\mathrm{M} \& \mathrm{E})$ process. It is vital that gender issues (as opposed to female representation in activities) are properly diagnosed and addressed.

As part of the empowerment process, the capacity development needs of the NGO and/or implementing agency staff should be examined and improved as necessary. Training should focus upon strengthening their ability to implement recommendations, carry out constructive dialogue with farmers, and enable them to shift course in the program as necessary in response to feedback. For this, a knowledge management program is essential. This should be simple to use and enable learning and action by all stakeholders.

Finally, the poorest and weakest in society should be encouraged to raise their concerns and desires, in separate meetings if necessary, to ensure that their needs are taken into account. 


\section{Acknowledgements}

This article was written with input from the other study team members: Margrethe Askegaard, Eduardo Lucas Vieito Reyes, and Rownok Jahan. We gratefully acknowledge the great help and insights of the people with whom we worked during in our time in West Bengal.

\section{References}

Das, S., \& Bose, K.(2010). Body mass index and chronic energy deficiency among adult Santals of Purulia District, West Bengal, India. International Journal of Human Science, 7(2). Retrieved from http://www.insanbilimleri.com/ojs/index.php/uib /article/viewDownloadInterstitial/1123/594\&ei= Wf wT7eDGurh0QGl-uj7Ag\&usg=AFQjCNH Mf29boIn4QGRluNtqNoSKaSHIg

Government of India National Sample Survey. (20042005). Cited in IFAD (2008a). India West Bengal Coastal Area Development Project Formulation Report. Main Report and Working Papers. Asia and the Pacific Division Programme Management Department. DRAFT. August 2008.

Government of West Bengal. (2007). Annual Report 2006-07, Department of Fisheries, Government of West Bengal. Cited in IFAD (2008a). India West Bengal Coastal Area Development Project Formulation Report. Main Report and Working Papers. Asia and the Pacific Division Programme Management Department. DRAFT. August 2008. Internal Paper. International Fund for Agricultural Development (IFAD). (2008a, August). India West Bengal Coastal
Area Development Project Formulation Report. Main Report and Working Papers. Asia and the Pacific Division Programme Management Department. DRAFT.

International Fund for Agricultural Development (IFAD).(2008b, April). Gender and Poverty Assessment Study - West Bengal Coastal Area Development Project. Report prepared by Shri Dipankar Saha. Cited in IFAD (2008a).

National Sample Survey Organisation [NSSO]. (2005). Public Distribution System and Other Sources of Household Consumption, 2004-2005, Table 3R. Cited in IFAD (2008a). India West Bengal Coastal Area Development Project Formulation Report. Main Report and Working Papers. Asia and the Pacific Division Programme Management Department. DRAFT. August 2008.

Scheduled castes and scheduled tribes. (2012, June 30). In Wikipedia, The Free Encyclopedia. Retrieved July 1, 2012, from http://en.wikipedia.org/w/ index.php?title $=$ Scheduled castes and scheduled tribes\&oldid $=500075304$

United Nations Development Programme, Project of the Government of India. (1999). Project Document, Sub-programme Budget Number IND/03/040/01/99. Retrieved from http://data.undp.org.in/seed/ Sundarbans PD.pdf

World Bank. (2009).The regional scene: South Asia's climate vulnerability and contribution to greenhouse gas emissions [Chapter 3]. Retrieved from http:// siteresources. worldbank.org/SOUTHASIAEXT/Resources/ Publications/448813-1231439344179/57261361232505590830/ch3SARclimateconsultJan2009.pdf 